\title{
INTELLIGENT TRANSPORT SYSTEM BASED ON RFID AND MULTI-AGENT APPROACHES
}

\author{
J. C. Q. Dias*, J. M. F. Calado**, A. L. Osório ${ }^{* * *}$ and L. F. Morgado** \\ *UMTE/ISEL - Instituto Superior de Engenharia de Lisboa \\ **IDMEC/ISEL - Instituto Superior de Engenharia de Lisboa \\ ***GIATSI/ISEL - Instituto Superior de Engenharia de Lisboa \\ Polytechnic Institute of Lisbon \\ (e-mail: \{jdias, jcalado\}@dem.isel.ipl.pt) \\ (e-mail: \{aosorio,lm\}@deetc.isel.ipl.pt) \\ PORTUGAL

\begin{abstract}
This paper presents an Intelligent Information and Communication Technology (IICT) architecture able to cope with the nowadays logistics operators challenges. The aim is to achieve an Intelligent Transport System based on RFID together with Multi-agent systems. Furthermore, the logistical platforms (production or distribution), as nodes of added value of supplying and distribution networks, are proposed as critical points of the visibility of the inventory, where these technological needs are more evident.
\end{abstract}

\section{INTRODUCTION}

The supply chain strategic management as a simultaneous local and global ("glocal") value chain is a collaborative/cooperative organization of stakeholders, many times in co-opetition, to perform a service to the customers respecting the time, place, price and quality levels. This complex scenario requires a tighter collaboration among the involved organizations and suggests the need of an innovative collaborative platform for the networked organizations considering they need to participate in collaborative processes (Osório, 2006). The proposal of a breeding environment in (Camarinha, 2004) as preparedness for an agile collaboration among organizations with a diversity of business, management and technological cultures, is strategic applied to a logistic supply chain considering a growing need for multi-modal operations and transports across countries.

In a Supply Chain Management (SCM) (Chen and Paulraj, 2004), planning of demand and supply for commodities in global value chain networks gains increasing importance in the process industry in the context of globalization. Hence, being logistics (Bowersox and Closs, 1996; Dornier et al., 1998) the art and science of managing the flows of goods or products, research on this field should aim to find the lowest cost carrier that provides the highest value, improving the visibility (monitoring and tracing) and velocity of the flow of materials and products and, reducing the amount and cost of carrying inventory or rolling stock, as well as, reducing or completely eliminating stocks in the supply chains interfaces or in other points of the suppliers network (Choi and Hong, 2002) and distribution channels (Dornier et al., 1998). During the last decades, several enterprises have achieved flexibility and increased competitiveness by implementing the "lean" or "just-intime (JIT)" principles developed at Toyota (Womack and Jones, 1996). Supply chain integration with transparent information flow is one of the key parameters to achieve such an approach. Thus, for logistics, Information and Communications 
Technologies (ICT) is particularly a time and embeddedness issue, providing the logistics operators the ability to cope with the mentioned new challenges. Because of ICT, freight distribution is within a paradigm shift between inventory-based logistics to replenishment-based logistics. Logistics is thus concomitantly concerned by compression distribution costs and time (Christopher, 2000; Dolgui et al., 2005). Time is a major issue for freight shipping as it imposes inventory holding and depreciation costs, which becomes sensitive for tightly integrated supply chains (Hasse and Rodrigue, 2004).

This paper aims at evidence and proposes the use of Radio Frequency Identification (RFID) technologies integrated to an Information and Communication Technologies (ICT) framework. The proposed framework is based on Distributed Artificial Intelligence (DAI) supported by a Multi-Agent System (MAS) approach, as the most value advantage of SCM in cooperative intelligent logistics systems. Furthermore, is proposed that logistical platforms (production or distribution), as nodes of added value of supplying and distribution networks, are the critical points of the visibility of the inventory, where these technological needs are more evident. The paper is organized as follows. Section 2 presents the Logistics as an integrated system that includes transportation operations in a worldwide market and presents the concept of SCM giving evidence that enabling technologies support the flows, specially, information flows. In Section 3 authors argue that ICT is a significant source of competitive advantage in SCM, proposing a multi-agent system approach including RFID to cope with the nowadays challenges of global value chains. Section 4 presents a case study and Section 5 provides some concluding remarks.

\section{SUPPLY CHAIN MANAGEMENT CHALLENGES}

New modes of production and new operations are concomitant with new modes of distribution, which brings forward the realm of logistics as science of physical distribution and supplying (Hesse and Rodrigue, 2004). Therefore, logistics represents an entire system of space/time/cost interdependencies and respective trade-offs. Freight distribution is now considered with more attention as productivity gains in manufacturing are increasingly derived from efficiency at terminals instead from efficiency of transportation modes (Rodrigue, 1999). Strategic management of the value chain is actually a phenomenon simultaneously local and global ("glocal") because through postponement operations it is possible customize, locally and add value to the inventory. Outbound logistics involves postponement that allows product differentiation and customization to be put off by building inventory as late as possible, that is, orders taken at the no-differentiated semi-finished inventory stage (Dornier et al., 1998). The classic trade theory neglects the role of transport and logistics particularly the fact that transport costs have a fundamental impact on the amount of trade and goods exchange. Hesse and Rodrigue (2004) argue that this perspective is mainly the result of a misinterpretation of role of the transport sector, freight alike, as a derived demand.

A supply chain, providing management of flows, is viewed as a network consisting of two or tree tiers of suppliers, manufacturers, distributors, retailers, and customers in a collaborative/cooperative organization of stakeholders, many times in co-opetition, to perform a service to the customers respecting the time, place, price 
and quality levels (Figure 1). At the operational level, this network supports three types of flows: Material flows, represent physical product flows from suppliers to customers as well as the reverse flows for product returns, servicing and recycling; Information flows, represent order transmission and order tracking, and coordinates the physical flows; Financial flows, represent credit terms, payment schedules, consignments and title ownership arrangements. The network, in turn, is supported by three pillars: Processes, embed the firm capabilities in logistics, new product development and knowledge management; Organizational structures, encompass a range of relationships from total vertical integration to networked companies as well as management approaches and performance measurement and reward schemes; Enabling technologies, include both process and information technologies. These approaches, in turn, typically lead to new forms of organizational structures (e.g., process orientation) and new forms of inter-organizational collaboration (e.g., outsourcing via third-party service providers or contract manufacturers). This transformation has coincided with the emergence of information and communication technologies (ICT) facilitating closer collaboration and promoting supply chain transparency. Success now hinges on a different set of criteria, where each company is racing to get the right product to the right place (or Just-in-Place, JIP) at the right time (or Just-in-Time, JIT) - and at the right cost. Therefore, real time information provided by ICT is fundamental to achieve the nowadays tasks related to an effective SCM. If a supply chain competes in a competitive environment, the strategic alignment between ICT (Eng, 2006) and business among upstream (suppliers network) and downstream (retailers network) partners will be the key factor for success. Nowadays collaborative logistics models need to be powered by advanced software systems and the Internet, allowing companies to expand collaborative logistic networks on a large scale, to reduce the costs of transportation and lower inventories, eliminating stocks.

\section{ICT FRAMEWORK BASED ON RFID AND MAS}

The use of an ICT framework based on intelligent multi-agents allows the integration of different supply chain strategies coping with the stocks reduction aim, in lean supply chains. Furthermore, in recognition of the increasing importance of globalization and the resulting need for greater, faster and more flexible communications, a framework is required to allow any company to establish itself in no time, make optimum use of their legacy applications and run efficiently with minimal cost input. Such a framework, very appealing to be based on intelligent multi-agents (Chen et al., 2007) corresponds to an emergent topic called e-logistics. Globalization means that the spatial frame for the entire economy has been expanded, implying the economy spatial expansion, more complex global economic integration and an intricate network of global flows and hubs (Rodrigue, 1999). Also in this context an ICT platform, may based on intelligent MAS, is particularly relevant as it helps strengthen the level of control distributors have over the supply chain. Finally, for many companies globalization is a dominating factor as companies seek to identify the best suppliers of services and products to meet their needs and help drive down costs, but only few have fully integrated and automated all components of their logistics process. However, successful implementation of 




Figure 1 - An integrated model of supply chain.

logistics activities (Bowesox and Closs, 1996) relies heavily on the integration of processes, practices and information to yield meaningful cost and time reductions. Investments on RFID technology will help to leverage reliable and timely RFID (Chao et al., 2007) data to achieve SCM optimal demand and logistics execution. RFID tag data can be tapped to enable complex decision-support with real-time data on supply chain and market conditions. These RFID solutions are designed to facilitate the gathering usage and storage of RFID data.

Taking into account the overall quoted aspects, global value chains in a globalization environment are complex and dynamic processes physically distributed and heterogeneous, where the communication nets among the several parts of the process force a distributed vision of the supply chain. Thus, the use of techniques such as DAI could be a good option to develop an Intelligent Information and Communication Technology (IICT) platform to support the emerging challenges of an effective supply chain management. Namely, methodologies based on MAS may be able to cope with the new challenges concerned with global value chains providing competitive advantages. An agent is a computer system that is capable of flexible autonomous action in dynamic, unpredictable, typically multi-agent domains (FIPA, 2007). In particular, the characteristics of dynamic and open environments in which, for example, heterogeneous systems must interact, span organisational boundaries, and operate effectively within rapidly changing circumstances and with dramatically increasing quantities of available information, like supply chain management, suggest that improvements on traditional computing models and paradigms are required. Thus, the need for some degree of autonomy, to enable components to respond dynamically to changing circumstances, is seen by many as fundamental, providing add value to global chain.

The MAS approach will bring to the supply chain management tasks the following advantages: Reliability, MAS are fault-tolerant (FT) and robust (redundant FT agents); Modularity and Scalability, instead of adding new capabilities to a system, agents can be added and deleted without breaking or interrupting the process; Adaptivity, agents have the ability to reconfigure themselves to accommodate new changes and events; Concurrency, agents are capable of reasoning and performing tasks in parallel, which in turn provides more flexibility and speeds up computation; and finally, Dynamics, agents can dynamically collaborate to share their resources and solve problems (Wooldridge, 2002).

In large-scale supply chains the supervision and management subsystems are distributed at the nodes of the network, and call for a large number of operators and programs which have to work together to accomplish the overall objectives. So, the 
need of DAI, and more precisely, the need of agents can be explained by the following topics: Problems are physically distributed; Problems are widely distributed and heterogeneous in functional terms; Networks force a distributed point of view. MAS can thus be seen as serious candidates for the construction of open, distributed, heterogeneous and flexible architectures, capable of offering highquality service for collective work, without imposing any a priori structure; The complexity of problems dictates a local point of view. Due to the complexity, the processes need the capability to adapt themselves to changes in the context of operations (changes in the operating system, in the database manager or the graphics interfaces, addition of other software and so on). Furthermore, because the distributed nature of MAS, they always assume that reasoning takes place locally, and because they are able to cope with the appearance or disappearance of agents even while the system is functioning, they are architectures especially suitable for providing the capabilities for systems evolution and adaptation; Software engineering is moving towards designs using concepts of autonomous interacting units. The history of software development shows that the creation of computer programs is following a course intended to lead to systems designed as assemblies of entities which will be more and more widely distributed, and making use of components which are more and more individualised and autonomous. MAS have an essential role to play here by acting as possible successors to object-oriented systems and combining local behaviours with autonomy and distributed decision making (Ferber 1999). Thus, the aspects mentioned above are some of the reasons to use DAI (agents) to support the supply chain management tasks, providing an ICT framework able to cope with the emerging challenges concerned with the globalization, giving competitive advantages to the global value chain.

\section{CASE STUDY}

Due to new corporate strategies, a concentration of logistics functions in certain facilities at strategic locations is prevalent. Many improvements in freight flows are achieved at terminals, distribution points, referred as "logistics platforms" (Aldin and Stahre, 2003). There are many types of structures designed as "logistical" platforms" (Dias, 2005) and, in Europe, there is an association of these platforms named, precisely, "Europlatforms" (Europlatforms, 2007). These infrastructures include the term "logistics" because they add value to the inventory, by many ways: one of them is time compression through cross-docking (Lambert and Cooper, 2000), transhipment, interoperability or intermodality; another through physical operations like inbound modularization and outbound postponement (Dornier et al., 1998); it can be mention, yet, the consolidation of goods, etc. In many cases, literature refers logistics platforms or logistical platforms as an industrial clusters and "distriparks", free zones, "dry ports", trading hubs networks (Europlatforms, 2007) and so on. Thus, in these physical infrastructures is possible find the needs of all relevant factors and sources of competitive advantage of the best value supply chains. It can be mention only the more significant, as follows: Visibility (monitoring, trace and track); Picking and Packing; Demotic and robotized warehousing and factoring; Modularization and postponement operations; Operations optimization; Efficient handling; Transportation management in real 
time; Interoperability and multimodality; Optimization of transhipment and crossdocking operations; Minimization of impedances; Collaborative suppliers network (ECR; QR/CR - Quick Response/Continuous Replenishment); Time and space compression; Efficient energy management; Orders monitoring and management; Networking connectivity; Real time information sharing; Communications to the front/back offices. These set of significant factors recommend the use of techniques like DAI as a good option to develop an Intelligent Information and Communication Technology (IICT) platform to support the referred emerging challenges in a generic logistical platform as defined by Europlatforms (2007). Namely, methodologies based on MAS approach may be able to cope with the new challenges concerned with global best value chains providing competitive advantages.

In order to investigate and to propose an inductive theory, a field approach was used as methodology, following the recommendations of Eisenhardt, 1989: The current approach is also based on the Grounded Theory, one of the most developed inductive research methods (Glaser and Strauss, 1967). This means that researchers are able to develop theory through comparative analysis because it is possible to look at the same event in different and several settings or situations (Easterby-Smitt et al., 1993). In these conditions the relevant proposition and other conclusions can be presented and applied in a generic case using evidences of several kinds of logistics platforms (case study as a method and strategy of direct research Mintzbeg, 1979). Multiple sources of evidence (authorities, logistics and transports operators, people responsible for departments of transportation, forwarders, production, distribution, and directors of logistical platforms, etc.) were used, as well the respective methodological triangulation (data, documents, perspectives, key-informants) and the creation of an indispensable chain of evidence (Yin, 1994).

Analyzing several logistical infrastructures, nine case studies, according, so as possible, to the concept referred as "Europlatforms", a conceptual model of an IICT system based on RFID and multi-agents, is depicted in Figure 2. Such an approach has been design for a generic logistics platform and a prototype is currently under development and test. Keeping in mind the growth of the World Wide Web and the rapid trend for e-Logistics to be use by the main logistics operators, in the current approach significant efforts has been done to develop standardised software models and technologies to support and enable the engineering of systems involving distributed computation. These efforts have been creating a rich and sophisticated context for the development of agent technologies.

Hence, a communication standard has been developed, which can be seen in Figure 2 as a Transport Management Service Bus (TMSB). The framework of the current approach is based on the principles of the so-called service-oriented architectures (SOAs) for distributed applications involving the creation of systems based on components, each of which provides predefined computational services (Huhns and Singh, 2005). Interfaces between the different software modules, ensured through a TMSB, can therefore be realised by agents that send and receive messages, while the services themselves are the resources characterised by the functionality provided. Agent technologies provide a way to conceptualise these systems as comprising interacting autonomous entities, each acting, learning or evolving separately in response to interactions in their local environments. Such a conceptualisation provides the basis for realistic computer simulations of the 


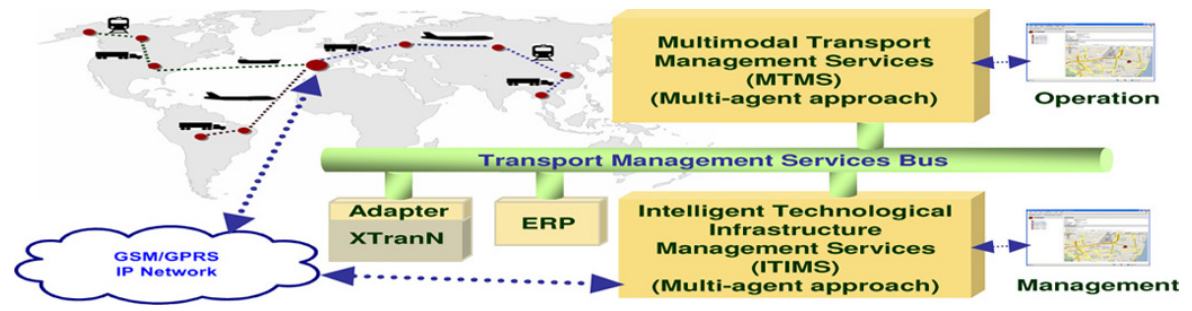

Figure 2 - Conceptual model for an IICT logistics platform.

operation and behaviour of a logistics platform and of design of control and intervention processes (Bullock and Cliff, 2004). However, despite a number of languages, frameworks, development environments, and platforms that have appeared in the literature (Luck et al., 2004), implementing MAS is still a complex task. In part, to manage MAS complexity, the research community has produced a number of methodologies that aim to structure agent development. Even if practitioners follow such methodologies during the design phase, there are difficulties in the implementation phase, partly due to the lack of maturity in both methodologies and programming tools. Further research is needed to move from analysis and design to code. Anyway, an IICT framework based RFID together with a MAS approach will provide great competitive advantages to overall global value chain based in each node of a network of logistics platforms.

\section{CONCLUSIONS}

It has been observed that the use of RFID technologies will enable a framework for enterprises to collaborate, plan monitor and execute, while optimally adapt in realtime to operate under unplanned occurrences in the extended supply chain. Therefore, Multi-agent systems promise to be a valuable software engineering solution for the development of an ICT framework, able to cope with the emerging challenges intrinsic to the supply chain management tasks, where the complexity and the distribution of the processes ask for new approaches. Furthermore, it has been proposed logistical platforms as nodes of added value of supplying and distribution networks, being the critical control points (track and trace) where the needs of valuable software engineering solution are more evident. In addition, the wide adoption of the Internet as an open environment, the increasing communication capabilities and the increasing popularity, in industry, of machine-independent programming languages, such as Java, make the adoption of multi-agent technology a feasible and a very interesting solution. The supply chain management includes most of the MAS characteristics: supply chains are dynamic, complex and large processes, spatially distributed and changeable in a dynamic, fragmented and global world. Thus, it can be said that the problems related to the supply chain management tasks fulfil the necessary requirements for a successful MAS application, providing competitive advantage to the global value chain.

Acknowledgements. The authors would like to acknowledge the cooperation of several key-informants and other persons in all firms and logistical platforms analyzed. Furthermore, the research work was partially funded by Project POCTI- 
SFA-10-46-IDMEC of FCT, funded by POCI 2010, POSC, FSE and MCTES.

\section{REFERENCES}

1. Aldin, N. and Stahre, F.. Electronic commerce, marketing channels and logistics platforms - a wholesaler perspective. Europ. J. Operationalt Research, 2003; 144 (2), pp. 270-279.

2. Bowersox, D. and Closs, D.J.. Logistical Management, the Integrated Supply Chain Process. Mc Graw-Hill, International Edition, 1996.

3. Bullock, S. and Cliff, D.. Complexity and Emergent Behaviour in ICT Systems. Foresight Report, Intelligent Infrastructure $\quad$ Futures, United Kingdom. http://www.foresight.gov.uk/Previous_Projects/Intelligent_Infrastructure_Systems/Reports_and_Publi cations/Intelligent_Infrastructure_Futures/ComplexityandEmergentBehaviour/, 2004.

4. Camarinha-Matos, L. M.; Afsarmanesh, H.. Supporting Infrastructures for New Collaborative Forms, in Collaborative Networked Organizations, pp. 175-192, Kluwer Acad. Publishers, 2004.

5. Chao, Chia-Chen, Yang, Jiann-Min Yang and Jen, Wen-Yuan. Determining technology trends and forecasts of RFID by a historical review and bibliometric analysis from 1991 to 2005. Technovation, 2007; 27 (5), pp. 268-279.

6. Chen, I.J. and Paulraj, A.. Understanding supply chain management: critical research and a theoretical framework. Int. Journal of Production Research, 2004; 42 (1), pp. 131-163.

7. Chen, Mu-Chen, Yang, Taho and Yen, Chi-Tsung. Investigating the value of Information Sharing in Multi-echelon Supply Chains. Quality \& Quantity, 2007; 41 pp.497-511.

8. Choi, T. Y. and Hong, Y.. Unveiling the structure of supply networks: case studies in Honda, Acura and DaimlerChrysler. J. Operat. Management, 2002; 20, pp. 469-493.

9. Christopher, M.. The agile supply chain competing in volatile markets. Ind. Marketing Manag., 2000; 29 (1), pp. 37-44.

10. Dias, J. C Q... Logística Global e Macrologística. Ed. Sílabo, $1^{\text {st }}$ ed,, , Lisboa, Portugal, April 2005.

11. Dolgui, A., Soldek, J. and Zaikin, O.. Supply chain optimisation: product/process design, facilities location and flow control. Applied Optimization, 94, Springer, ISBN : 0-387-23566-3, 2005.

12. Dornier, P. P., Ernest, R., Fender, M. and Kouvelis, P.. Global Operations and Logistics -Text and Cases. John Wiley \& Sons, Inc., 1998.

13. Easterby-Smith, M., Thorpe, R., and Lowe, A.. Management Research: an Introduction. Sage: London, 1993.

14. Eisenhardt, K. M.. Building theories from case study research. Academy of Manag. Review, 1989; 14 (4), pp. 532-550.

15. Eng, T.-Y.. Mobile supply chain management: Challenges for implementation. Technovation, 2006; 26, pp. 682-686.

16. Europlatforms. http://www.eutp.org/download/ClusterPapers/Europlatforms.ppt (site visited 07/7/15).

17. Ferber, J.. Multi-agent systems, An Introduction to Distributed Artificial Intelligence. AddisonWesley. Harlow, England, 1999.

18. FIPA. The foundation for intelligent physical agents. http://www.fipa.org/, 2007.

19. Glaser, D.G. and Strauss, A. L.. The Discovery of Grounded Theory: Strategies for Qualitative Research. Alding, New York, 1967.

20. Hesse, M., and Rodrigue, J-P.. The transport geography of logistics and freight distribution. Journal of Transport Geography, 2004; 12 (3), pp. 171-184.

21. Lambert and Cooper. Issues in supply chain management. Ind. Mark. Manag., 2000; 29, pp. 65-83.

22. Luck, M., Ashri, R. and d'Inverno M.. Agent-Based Software Development. Artech House, Inc. Boston, U.S.A, 2004.

23. Mintzberg, H.. An Emerging Strategy of "direct" Research. Adminis. Science Quarterly, 1979; 24 (4), pp. 582-589.

24. Osório, A. L. and Camarinha-Matos, L. M.. Towards a Distributed Process Execution Platform for Collaborative Networks; 7th IFIP Int. Conf. on Information Technology for Balanced Automation Systems in Manufacturing, proc. published by Springer; Ontario, Canada, 2006; 4-6 September.

25. Rodrigue, J.-P.. Globalization and the Synchronization of Transport Terminals. J.l of Transport Geography, 1999; 7, pp. 255-261.

26. Womack, J. P. and Jones, D. T.. Lean Thinking: Banish Waste and Create Wealth in your Corporation. Simon and Schuster, New York and London, ISBN 684810352, 1996.

27. Wooldridge, M.. An Introduction to Multiagent Systems. J. Wiley \& Sons, Chichester, England, 2002.

28. Yin, R. K.. Case study research: design and methods. $2^{\text {nd }}$ Edition, Sage, London, 1994. 